\title{
Perceptions of normal and abnormal ejaculatory latency times: an observational study in Ghanaian males and females
}

\author{
Nafiu Amidu ${ }^{*}$, William K. B. A. Owiredu², Peter P. M. Dapare ${ }^{1}$ and Benedict B. Antuamwine ${ }^{1}$
}

\begin{abstract}
Background: This cross-sectional study aimed at quantifying the perceptions of Ghanaian men and women on how long they thought sex should last, from intromission until ejaculation.

Method: A random sample of 568 heterosexual men and women within the Kumasi Metropolis was surveyed from December 2009 to February 2010. The question of primary interest in the present study includes perceived intravaginal ejaculatory latency (IELT), in minutes, for four different conditions: "adequate," "desirable,"'too short," and "too long" IELT.

Results: The interquartile range for the respondent's judgment of an "adequate" length for IELT was from 7.0 to $20.3 \mathrm{~min}$; "desirable" from 10.0 to 25.0 min; "too short" from 2.0 to 5.0 min; "too long" from 10.5 to 60.0 min. However, the "actual" IELT (i.e. what the respondents are capable of doing) as found in this study was from 6 to 15 min. Ghanaian perceptions about ejaculatory latencies were in part consistent with data from Germany and contrary to data from the USA on ejaculatory latency and were not affected by age or educational level.

Conclusion: These results suggest that the average Ghanaian believes that intercourse that lasts $7.0-25.0 \mathrm{~min}$ is normal. Dissemination of the present finding to the public may modify their expectations for IELT which will lead to a realistic replica of sexuality and hence help prevent sexual disappointments and dysfunctions. It will also be beneficial to couples who are being treated for sexual problems by normalizing their expectations.
\end{abstract}

Keywords: Intravaginal ejaculatory latency, Perception, Premature ejaculation, Ghana

\section{Background}

An evidence-based definition of premature ejaculation is important for the diagnosis and treatment of men who complain of premature ejaculation (PE) [1]. The consecutive Work Groups on Sexual Disorders of the Diagnostic and Statistical Manual of Mental Disorders (DSM) gained popularity for its classification of PE. These definitions by DSM, however, have been heavily criticized in recent studies for its vagueness and absence of a short ejaculation time criterion cutoff score [2]. The International Society for Sexual Medicine by consensus formulated the first evidence-based definition of lifelong PE in 2008,

\footnotetext{
*Correspondence: anafiu@uds.edu.gh

${ }^{1}$ Department of Biomedical Laboratory Sciences, School of Allied Health

Sciences, University for Development Studies, Tamale, Ghana

Full list of author information is available at the end of the article
}

where short ejaculation time was defined as an ejaculation occurring within $1 \mathrm{~min}$ after vaginal penetration, with an inability to delay ejaculation and with personal negative consequences such as bother or avoidance of sexual activities [3].

A lot of men, however, complain of PE at longer durations of the intravaginal ejaculation latency time (IELT). To include these men in a classification system of PE, Waldinger et al. $[4,5]$ proposed the existence of two other PE subtypes; natural variable PE and premature-like ejaculatory dysfunction, in addition to the earlier proposed subtypes, lifelong and acquired PE. In contrast to men with lifelong PE, men with premature-like ejaculatory dysfunction complain of PE while having normal or even long durations of IELT. Notably, Waldinger emphasized 
that the four PE subtypes were characterized by different etiology and pathophysiology [4].

In two stopwatch-measured surveys in the general male population of five Western countries, the median IELT appeared to be 5.4 and $6.0 \mathrm{~min}$, respectively $[5,6]$. In these surveys, the prevalence of IELTs of less than 1 min was about $2.5 \%$, whereas $28 \%$ of the investigated men considered themselves to have a too short IELT. The mean IELT of these men was $4.9 \mathrm{~min}$. The existence of the four PE subtypes has been confirmed by Serefoglu et al. $[7,8]$ who showed that the prevalence of lifelong PE is low in the general Turkish male population and high in an outpatient clinic for urology. In addition, and as predicted by Waldinger, the prevalence of premature-like ejaculatory dysfunction is relatively high in the general Turkish male population and low in an outpatient clinic for urology $[7,8]$.

Despite the majority of studies on the duration of IELTs with or without stopwatches occurring within Western and Asian countries, there are no data so far derived from an African perspective. Due to the variations existing between Western and African countries in terms of cultural differences, socioeconomic levels and the quality of psychosexual relationships, which may influence the perception of how long IELT should last during intercourse, it will be interesting to find out how this will be perceived in one or more African countries.

Additionally, it will be fascinating to know the general perception of men and women regarding normal intercourse duration, one that may be a point of contention among both sexes. The aim of the current study among a sample of Ghanaian men and women was therefore to investigate the Ghanaian perception on normal and abnormal intercourse duration. To our knowledge, this is the first study on the perception of IELT conducted among an African population.

\section{Methods \\ Study population}

This epidemiological cross-sectional study population comprised heterosexual, adult Ghanaian male and female subjects of age 17-64 years. Questionnaires were distributed to a total of 900 heterosexual men and women randomly within the Kumasi Metropolis who had attained at least basic education (i.e. at least junior high school). Randomization of the study population was carried out by handing out questionnaires to target groups at schools, canteens, bus terminals, automechanic shops and offices. Kumasi is the second largest city in Ghana after the capital (Accra) with a population of about 1.5 million. The inhabitants are predominantly Christians, forming about $80 \%$ of the population and have Ashanti as the largest ethnic group. The participation of the respondents who were all indigenes of Ghana was voluntary and informed consent was obtained from each of them. The study was approved by the local Committee on Human Research, Publication and Ethics (CHRPE).

\section{Measurements}

Questions regarding perception of normal and abnormal IELT were adopted and modified from a study among sex therapists conducted in the USA and Canada [9]. The respondents were asked to provide information on their demographics (age, sex, occupation, educational level, marital status, etc.) and were to give their opinion on questions about IELT with responses such as "too short," "adequate," "desirable," or "too long."

Additionally, the respondents were asked to give their opinion on several other questions including; "What is an adequate amount of time to elapse in sex from penile penetration of the vagina to ejaculation?" which was asked in four different ways, with the italicized word changing from adequate, to desirable, to too short and then to too long. Respondents were also asked to estimate the time in minutes that they normally stay in sex from penile penetration of the vagina to ejaculation, the IELT [10]. This was an estimated time response.

\section{Statistical analysis}

The data were presented as mean \pm SD or percentages. Continuous data were analyzed using unpaired $t$ test, while categorical variable were analyzed using Fischer's exact test. In all statistical tests, a value of $P<0.05$ was considered significant. All analysis were performed using SigmaPlot for Windows, Version 11.0, (Systat Software, Inc. Germany) http://www.systat.com.

\section{Results}

Six hundred and twenty two (69 \%) of the 900 distributed questionnaires were returned. Twenty-three (3.7\%) of these respondents indicated no sexual experience and felt unable to provide responses to the questions. Thirtyone respondents $(5 \%)$ did not provide a time estimate response for at least one of the IELT questions. However, they indicated that the interpretation of IELT depends on the partner and/or the number of times the sex act was performed. The remaining 568 (91.3\%) respondents had a mean age \pm SD of $28.7 \pm 0.6$ years (range $17-60$ years) and were fairly distributed between married ( 43\%) and never married (single) subjects. Majority of the respondents were males $(85 \%)$ and had attained tertiary education $(86 \%)$ while very few of the respondents smoked $(7.4 \%)$ as shown in Table 1.

When a respondent's response is in a range (e.g. 3-7 $\mathrm{min}$ ), the midpoint of the range (e.g. $5 \mathrm{~min}$ ) is calculated and used as the response. Though the female 
Table 1 Demographic characteristics of the studied population stratified by gender

\begin{tabular}{|c|c|c|c|c|}
\hline Variable & Total (568) & Male (483) & Female (85) & $P$ value \\
\hline Age (years) & $28.7 \pm 0.6$ & $29.7 \pm 0.7$ & $22.8 \pm 0.8$ & $<0.0001$ \\
\hline Married & 242 (42.6 \%) & $217(44.9 \%)$ & $25(29.4 \%)$ & 0.0009 \\
\hline \multicolumn{5}{|c|}{ Educational level } \\
\hline Basic & $7(1.2 \%)$ & $7(1.5 \%)$ & $0(0.0 \%)$ & 0.2641 \\
\hline Secondary & 97 (17.1\%) & 74 (15.3 \%) & $23(27.1 \%)$ & 0.008 \\
\hline Tertiary & 464 (81.7\%) & 402 (83.2 \%) & $62(73.0 \%)$ & 0.0237 \\
\hline \multicolumn{5}{|l|}{ Exercise } \\
\hline Yes & 291 (51.2 \%) & 252 (52.2 \%) & 39 (45.9\%) & 0.2089 \\
\hline \multicolumn{5}{|l|}{ Smoking } \\
\hline Yes & $42(7.4 \%)$ & $42(8.7 \%)$ & $0(0.0 \%)$ & 0.0047 \\
\hline \multicolumn{5}{|c|}{ Alcohol intake } \\
\hline Yes & $321(56.5 \%)$ & 294 (60.9 \%) & 27 (31.8\%) & $<0.0001$ \\
\hline
\end{tabular}

Results are presented as mean \pm standard deviation

IELT estimated intravaginal ejaculatory latency time

respondents were significantly younger than their male counterparts and the married respondents were also significantly older than the single respondents, their perception about IELTs were generally similar. However, the perception of married respondents about "adequate" IELT was significantly higher $(17.9 \pm 1.9)$ than those who were single $(13.7 \pm 1.0)(P=0.0404)$ as shown in Table 2.

The questions of primary interest in the present study involved respondents' definitions of "adequate" and "desirable" IELTs. The mean \pm SD for these variables were, respectively, $15.4 \pm 1.0$ and $18.8 \pm 1.3 \mathrm{~min}$, with interquartile ranges (IQRs) 7.0-20.3 and 10.0-25.0 min, respectively. (The IQR represents the responses of the middle $50 \%$ of respondents, the range from the 25 th percentile to the 75th percentile of responses.) The respondents were also asked the definitions for IELTs that were "too short" or "too long". The mean \pm SD times for these were $4.9 \pm 0.6$ and $36.7 \pm 2.4 \mathrm{~min}$, respectively. IQRs for these variables were 2.0 to 5.0 and 10.5 to $60.0 \mathrm{~min}$, respectively. The mean as well as the IQR for the "actual" IELT (i.e. what the respondents are capable of doing) as found in this study were $9.4 \pm 1.6$ and 6 to $15 \mathrm{~min}$, respectively (Table 2).

Box plots showing the medians, IQRs and range of scores for all latency questions based on gender and marital status are shown in Fig. 1.

Overall, only $25 \%$ of men and women perceived "adequate" IELT to last for 3-7 min, while about $74 \%$ perceived "adequate" IELT to last for more than 3-7 min (Table 2).

Though about $68 \%$ of single subjects perceived "adequate" sex to last for more than 3-7 min, about $50 \%$ perceived "desirable" sex to last for more than $13 \mathrm{~min}$, $57 \%$ perceived "too short" sex to be greater than $2 \mathrm{~min}$ and $38 \%$ perceived "too long" sex to last for more than $30 \mathrm{~min}$. The figures were $81 \%, 66 \%, 71 \%$ and $45 \%$, respectively for "adequate", "desirable", "too short" and "too long" among married respondents (Table 3).

To investigate whether demographic variables (age, marital status and educational level) were associated with perceptions of IELTs (too short, adequate, desirable or too long), the Pearson correlation matrix was employed. Apart from age that had a significant but negative correlation $(r=-0.23 ; P<0.01)$ with education, none of the demographic variables showed a statistically significant association with any of the latency variables. The latency variables, however, generally gave a significant positive correlation with each other as shown in Table 4.

\section{Discussion}

The present study which is the first of its kind in our community, a very conservative community, compared the actual, adequate, desired, too short and too long IELT of heterosexual men and women who were either single or married. Even though estimates of the duration of IELT experienced by men and women do not differ significantly from their perceived duration of adequate, desired, too short and too long IELT, the men's estimates of actual IELT they experience was about 1.4 min longer than that of women. Though the difference did not reach a significant level, the women consistently estimated higher

Table 2 General characteristic of the studied population stratified by gender and marital status

\begin{tabular}{|c|c|c|c|c|c|c|c|}
\hline Parameters & Total & Male & Female & $P$ value & Single & Married & $P$ value \\
\hline Age (years) & $28.7 \pm 0.6$ & $29.7 \pm 0.7$ & $22.8 \pm 0.8$ & $<0.0001$ & $25.2 \pm 0.6$ & $33.1 \pm 1.0$ & $<0.0001$ \\
\hline Actual IELT (min) & $9.4 \pm 1.6$ & $9.6 \pm 1.8$ & $8.2 \pm 2.3$ & 0.7653 & $10.5 \pm 2.7$ & $8.1 \pm 1.4$ & 0.4490 \\
\hline Adequate IELT (min) & $15.4 \pm 1.0$ & $15.1 \pm 1.1$ & $17.1 \pm 2.8$ & 0.4796 & $13.7 \pm 1.0$ & $17.9 \pm 2.0$ & 0.0404 \\
\hline Desirable IELT (min) & $18.8 \pm 1.3$ & $18.8 \pm 1.4$ & $19.1 \pm 3.3$ & 0.9383 & $18.2 \pm 1.5$ & $19.6 \pm 2.3$ & 0.5792 \\
\hline Too short IELT (min) & $4.9 \pm 0.6$ & $4.8 \pm 0.6$ & $5.4 \pm 1.5$ & 0.6896 & $4.3 \pm 0.5$ & $5.6 \pm 1.1$ & 0.2404 \\
\hline Too long IELT (min) & $36.7 \pm 2.4$ & $36.4 \pm 2.8$ & $38.4 \pm 4.2$ & 0.7769 & $36.0 \pm 3.5$ & $37.7 \pm 3.3$ & 0.7295 \\
\hline
\end{tabular}

Results are presented as mean \pm standard deviation

IELT estimated intravaginal ejaculatory latency time 

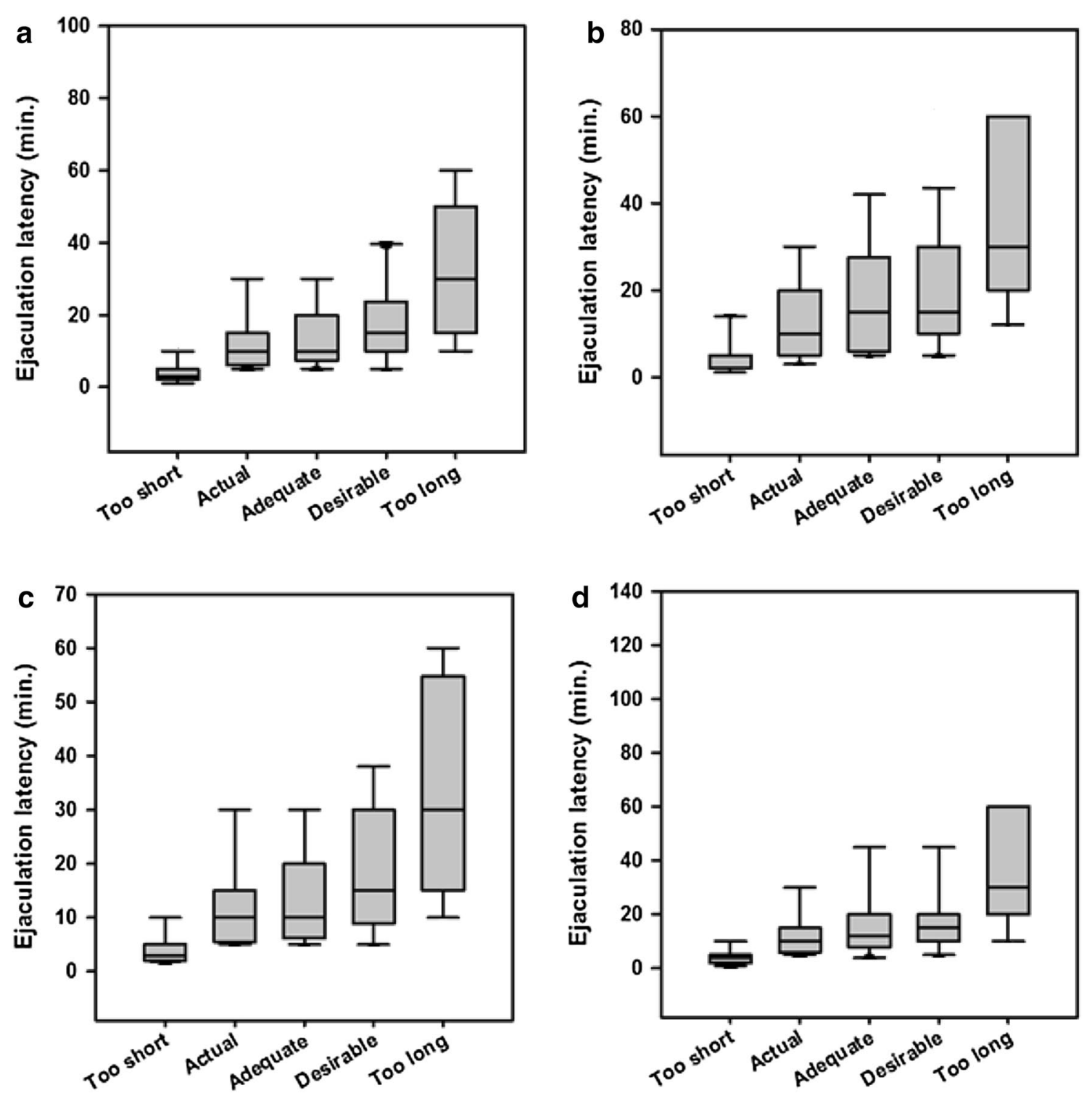

Fig. 1 Box plots of respondent's ratings of lengths of different categories of ejaculatory latencies. The lower and upper margins of the box represent the 25th and 75th percentiles, with the extended arms representing the 10th and 90th percentiles, respectively. The median is shown as the horizontal line within the box. A male, $B$ female, $C$ single and $D$ married

perceived IELTs than their male counterparts (Table 2), a trend that was similarly observed by Waldinger and associates among a Dutch cohort of men with lifelong PE [11].Whereas this finding is similar to data from Germany, it is at variance with data from the USA [12]. This could partly be due to the fact that women are more open about their sexual life than men, at least in relationships and dating [13, 14]. Cultural as well as methodological differences could also contribute to this disparity.

Our study shows that the IQR for perceived adequate IELT is around 7.0-20.3 min. This is longer than what
Western sex therapists deem as adequate IELT and borders around what many experienced sex therapists may consider to be too long [9]. The IQR of IELTs perceived by experienced Western sex therapists to be "adequate" ranges from 3 to $7 \mathrm{~min}$.

There is also an overlap between what respondents consider to be an adequate latency and a "desirable" IELT, with the respondents perceiving longer IELTs $(\mathrm{IQR}=10.0-25.0 \mathrm{~min})$ as more desirable. Combining these two IQRs, it sounds reasonable to say that an IELT of 7-25 $\mathrm{min}$ is perceived by respondents as normal. 
Table 3 The proportions of respondents who perceived intravaginal ejaculation latency above (i.e. high) and below (i.e. low) the reference interval for "adequate", "desirable", "too short" and "too long" IELT

\begin{tabular}{|c|c|c|c|c|c|c|c|}
\hline Parameters & Total & Male & Female & $P$ value & Single & Married & $P$ value \\
\hline \multicolumn{8}{|c|}{ Adequate (3-7) } \\
\hline Low & 4/556 (0.7\%) & 4/472 (0.8 \%) & 0/84 (0.0 \%) & 1.0000 & 0/324 (0.0 \%) & 4/236 (1.7\%) & 0.0311 \\
\hline High & $412 / 556(74.1 \%)$ & $352 / 472(74.6 \%)$ & $60 / 84(71.4 \%)$ & 0.5889 & $220 / 324(67.9 \%)$ & 192/236 (81.4 \%) & 0.0005 \\
\hline \multicolumn{8}{|c|}{ Desirable (7-13) } \\
\hline Low & $92 / 568$ (16.2\%) & 40/488 (16.4\%) & 12/84 (14.3 \%) & 0.0970 & 48/324 (14.8 \%) & 40/236 (16.9\%) & 0.5568 \\
\hline High & $316 / 568$ (55.6\%) & 272/488 (55.7\%) & $44 / 84(52.4 \%)$ & 0.6349 & $160 / 324(49.4 \%)$ & 156/236 (66.1 \%) & $<0.0001$ \\
\hline \multicolumn{8}{|c|}{ Too short $(1-2)$} \\
\hline Low & 0/556 (0.0 \%) & 0/476 (0.0 \%) & 0/84 (0.0 \%) & 1.0000 & 0/324 (0.0 \%) & 0/236 (0.0 \%) & 1.0000 \\
\hline High & $352 / 556(63.3 \%)$ & $302 / 476$ (63.4 \%) & $50 / 84$ (59.5 \%) & 0.5406 & $184 / 324$ (56.8 \%) & 168/236 (71.2 \%) & 0.0005 \\
\hline \multicolumn{8}{|c|}{ Too long (10-30) } \\
\hline Low & $32 / 564(5.7 \%)$ & $28 / 480$ (5.8 \%) & 4/84 (4.8 \%) & 1.0000 & 20/324 (6.2 \%) & $12 / 240(5.0 \%)$ & 0.5863 \\
\hline High & 232/564 (41.1\%) & 192/480 (40.0 \%) & $40 / 84$ (47.6 \%) & 0.2293 & $124 / 324(38.3 \%)$ & $108 / 240(45.0 \%)$ & 0.0826 \\
\hline
\end{tabular}

Table 4 Pearson correlation coefficients of demographic variables and perceptions of ejaculatory latencies

\begin{tabular}{|c|c|c|c|c|c|c|c|}
\hline Marital status & & Education & Actual & Adequate & Desirable & Too short & Too long \\
\hline Age & 0.06 & $-0.23^{* *}$ & 0.05 & -0.05 & -0.02 & -0.07 & -0.03 \\
\hline Marital status & & 0.07 & 0.06 & -0.15 & -0.11 & -0.09 & -0.05 \\
\hline Education & & & 0.04 & 0.07 & -0.12 & 0.08 & 0.05 \\
\hline Actual & & & & 0.16 & $0.35^{* * *}$ & $0.24^{* *}$ & $0.56^{* * *}$ \\
\hline Adequate & & & & & $0.56^{* * *}$ & $0.21^{*}$ & $0.42^{* * *}$ \\
\hline Desirable & & & & & & $0.23^{* *}$ & $0.68^{* * *}$ \\
\hline Too short & & & & & & & $0.25^{* *}$ \\
\hline
\end{tabular}

* Correlation is significant at the 0.05 level (2-tailed)

** Correlation is significant at the 0.01 level (2-tailed)

*** Correlation is significant at the 0.001 level (2-tailed)

This may have consequences for men who are not satisfied with their ejaculation time and may erroneously be classified as having premature ejaculation when their actual ejaculation time is less than their desirable IELT. The current study underlines the existence of the PE subtype, premature-like ejaculatory dysfunction as recently proposed by Waldinger et al. [11], where both men and women in the general population who have normal or even long IELT duration are not satisfied with IELT values which are normal in the general male population as has been measured by stopwatch in two population surveys $[5,6]$. Our findings can also be compared to previous reports of the same authors $[5,6]$ that about $30 \%$ of men in Western countries are not satisfied with normal IELT values.

In the current group of African subjects, married respondents do not only perceive longer time as being "adequate," "desirable," "too short," or "too long" IELTs, but also a significantly higher proportion (about 13, 17, 14 and $7 \%$ more than the single respondents, respectively) have a perceived time which is more than what
Western sex therapists recommend [9]. The reasons for these discrepancies are not clearly shown from this study, but may be culturally influenced. Future research with objective methods, such as the use of a stopwatch, will show that the actual IELT duration in certain African cohorts is indeed longer than that generally measured in Western countries and these differences may perhaps be explained by biological or genetic factors [15]. However, in general, the actual ejaculation latency time depends on a variety of contextual, psychological, behavioral and relationship partner variables [16].

On comparing actual to desired time, both sexes wanted an increase in the length of both variables. The men desired an increase from a reported time of $9.6 \mathrm{~min}$ in intercourse to a desired length of $18.8 \mathrm{~min}$, whereas the women desired an increase from 8.2 to $19.1 \mathrm{~min}$. With both men and women desiring that intercourse lasts about twice as long as the selfreported length, it is conceivable that this may lead to distress, displeasure and ultimately to the purchase of sex-enhancing medication as observed currently 
among Ghanaians (Amidu, personal observation). However, one should be cautious not to diagnose these men as having PE. Recently, men who are not satisfied with their IELT while having a normal or even long IELT duration have been classified as having premature-like ejaculatory dysfunction [1]. According to Waldinger et al, this PE subtype has a clearly different etiology and pathogenesis than lifelong PE or acquired PE [4]. This Ghanaian men cohort is most likely the group with premature-like ejaculatory dysfunction. In the general male population, the prevalence of this PE subtype is high, whereas in clinics of sexual medicine, it is rather low. The prevalence of sexual dysfunction (SD) and PE among Ghanaian men are 66 and $65 \%$ respectively [17], $73 \%$ SD rate among the women [18] and $80 \%$ PE rate among men presenting with various medical conditions [19].

From this study, respondent characteristics did not influence their perceptions of normal and abnormal IELTs. Neither age nor marital status was associated with perceived IELT, suggesting that the respondents' judgments were not based on their personal experiences or marital status. Similarly, perceived latencies did not vary with educational level. This suggests that for these respondents, at least continuing education gave them a shared perspective.

For people with existing SD, it will be advisable for their sex therapists in Ghana to assess the actual latency, since self-estimate may be discrepant from actual latency. Afterward, the patient's desired latency should be determined and this objective discussed in the context of the data reported here and that of the sex therapists (i.e. sex therapists consider coitus that lasts as little as $3 \mathrm{~min}$ to be of adequate length) [9]. This can help shift the patient away from experiencing distress or interpersonal difficulty and prevent the patient from perceiving his or her situation as a problem [20].

The study is in agreement with that of Waldinger [20] who suggested that various counseling methods, and not drug treatment, should be used in treating individuals who present with premature-like ejaculatory disorders due to their actual IELTs being perceived as rapid ejaculation. Even though a person's understanding of sexual functioning is related to inherent standards and beliefs, it can greatly be modified by the type of formal and informal education received from the society [9], including pornographic movies. Since expectation is known to be determined by stereotypes and not reality [21], dissemination of the results of the present study can help modify individual expectations about sexual functioning and performance. By dissociating expectations from fantasy to a realistic replica of sexuality, the present results may help prevent sexual disappointments and dysfunctions.
One major limitation of this study is that participants were asked to reduce a complex human sexual behavior to a single number. Despite the fact that the majority of respondents provided the requested values, such values would not be able to explain the complexity of human behavior. Due to the difficulty in determining at what time during intercourse the reading starts as the couple may move to and from vaginal encapsulation of the penis [21], the usage of intravaginal ejaculatory latency as an outcome measure is further confounded. Furthermore, this study used self-report to measure time and it is possible that there may be a biased estimate of the length of intercourse.

\section{Conclusion}

The results from the present study provides a realistic as well as a baseline model of Ghanaian sexuality and would be useful both in treating people with sexual concerns and dysfunctions, and with wider applications in preventing the onset of SD.

\section{Authors' contributions}

NA and WKBAO developed the concept and designed the study. NA, WKBAO, PPMD and BBA administered the questionnaire, analyzed and interpreted the data. NA, PPMD and BBA drafted the manuscript. NA, WKBAO, PPMD and BBA revised the manuscript for intellectual content. All authors read and approved the final manuscript.

\section{Author details}

1 Department of Biomedical Laboratory Sciences, School of Allied Health Sciences, University for Development Studies, Tamale, Ghana. ${ }^{2}$ Department of Molecular Medicine, School of Medical Sciences, College of Health Sciences, Kwame Nkrumah University of Science and Technology, Kumasi, Ghana.

\section{Compliance with ethical guidelines}

\section{Competing interests}

The authors declare that they have no competing interests.

Received: 20 January 2015 Accepted: 1 September 2015

Published online: 04 September 2015

\section{References}

1. Waldinger MD, Schweitzer DH. The use of old and recent DSM definitions of premature ejaculation in observational studies: a contribution to the present debate for a new classification of PE in the DSM-V. J Sex Med. 2008;5(5):1079-87.

2. Waldinger MD, Schweitzer $\mathrm{DH}$. Changing paradigms from a historical DSM-III and DSM-IV view toward an evidence-based definition of premature ejaculation. Part I-validity of DSM-IV-TR. J Sex Med. 2006;3(4):682-92.

3. McMahon CG, Althof SE, Waldinger MD, Porst H, Dean J, Sharlip ID, Adaikan PG, Becher E, Broderick GA, Buvat J, et al. An evidence-based definition of lifelong premature ejaculation: report of the International Society for Sexual Medicine (ISSM) ad hoc committee for the definition of premature ejaculation. J Sex Med. 2008;5(7):1590-606.

4. Waldinger MD. Premature ejaculation: different pathophysiologies and etiologies determine its treatment. J Sex Marital Ther. 2008;34(1):1-13.

5. Waldinger MD, Quinn P, Dilleen M, Mundayat R, Schweitzer DH, Boolell M. A multinational population survey of intravaginal ejaculation latency time. J Sex Med. 2005:2(4):492-7. 
6. Waldinger MD, McIntosh J, Schweitzer DH. A five-nation survey to assess the distribution of the intravaginal ejaculatory latency time among the general male population. J Sex Med. 2009;6(10):2888-95.

7. Serefoglu EC, Cimen HI, Atmaca AF, Balbay MD. The distribution of patients who seek treatment for the complaint of ejaculating prematurely according to the four premature ejaculation syndromes. J Sex Med. 2010;7(2 Pt 1):810-5.

8. Serefoglu EC, Yaman O, Cayan S, Asci R, Orhan I, Usta MF, Ekmekcioglu $\mathrm{O}$, Kendirci M, Semerci B, Kadioglu A. Prevalence of the complaint of ejaculating prematurely and the four premature ejaculation syndromes: results from the Turkish Society of Andrology Sexual Health Survey. J Sex Med. 2011;8(2):540-8.

9. Corty EW, Guardiani JM. Canadian and American sex therapists' perceptions of normal and abnormal ejaculatory latencies: how long should intercourse last? J Sex Med. 2008;5(5):1251-6.

10. Waldinger MD, Hengeveld MW, Zwinderman AH. Paroxetine treatment of premature ejaculation: a double-blind, randomized, placebo-controlled study. Am J Psychiatry. 1994;151(9):1377-9.

11. Waldinger MD, Hengeveld MW, Zwinderman AH, Olivier B. An empirical operationalization study of DSM-IV diagnostic criteria for premature ejaculation. Int J Psychiatry Clin Pract. 1998;2(4):287-93.

12. Multi country concept (MCC). Multi country concept evaluation and assessment of PE incidence study. The Alza Corporation. 2002 (data on file).

13. Byers ES, Demmons S. Sexual satisfaction and sexual self-disclosure within dating relationships. J Sex Res. 1999;36:180-9.
14. MacNeil S, Byers ES: Contributions of communication and understanding to sexual satisfaction among dating couples. In: Paper presented at the meeting of the Society for the Scientific Study of Sexuality: 1999; St. Louis; 1999.

15. Janssen PK, Bakker SC, Rethelyi J, Zwinderman AH, Touw DJ, Olivier $\mathrm{B}$, Waldinger MD. Serotonin transporter promoter region (5-HTTLPR) polymorphism is associated with the intravaginal ejaculation latency time in Dutch men with lifelong premature ejaculation. J Sex Med. 2009;6(1):276-84

16. Perelman MA. A new combination treatment for premature ejaculation: a sex therapist's perspective. J Sex Med. 2006:3(6):1004-12.

17. Amidu N, Owiredu WKBA, Woode E, Addai-Mensah O, Gyasi-Sarpong KC, Alhassan A. Prevalence of male sexual dysfunction among Ghanaian populace: myth or reality? Int J Impot Res. 2010;22(6):337-42.

18. Amidu N, Owiredu WKBA, Woode E, Addai-Mensah O, Quaye L, Alhassan A, Tagoe EA. Incidence of sexual dysfunction: a prospective survey in Ghanaian females. Reprod Biol Endocrinol. 2010;8:106.

19. Amidu N, Owiredu WKBA, Woode E, Appiah R, Quaye L, Gyasi-Sarpong CK. Sexual dysfunction among Ghanaian men presenting with various medical conditions. Reprod Biol Endocrinol. 2010;8:118.

20. Waldinger MD. The need for a revival of psychoanalytic investigations into premature ejaculation. J Men's Health Gend. 2006;3(4):390-6.

21. Miller SA, Byers ES. Actual and desired duration of foreplay and intercourse: discordance and misperceptions within heterosexual couples. J Sex Res. 2004;41(3):301-9.

\section{Submit your next manuscript to BioMed Central and take full advantage of:}

- Convenient online submission

- Thorough peer review

- No space constraints or color figure charges

- Immediate publication on acceptance

- Inclusion in PubMed, CAS, Scopus and Google Scholar

- Research which is freely available for redistribution

Submit your manuscript at 